\title{
AC 2010-1744: ENHANCING AEROSPACE ENGINEERING EDUCATION THROUGH FLIGHT TESTING RESEARCH
}

\section{Kerri Phillips, West Virginia University}

Kerri Phillips is a doctoral student in aerospace engineering at West Virginia University. She obtained bachelor's degrees in aerospace engineering and mechanical engineering from WVU in December 2007 and was named a Barry M. Goldwater Scholar and to the USA Today All-Academic Team. She has participated in internships with both NASA and Boeing and her research interests include flight controls, flight testing, and aircraft system identification.

\section{Giampiero Campa, The MathWorks, Inc.}

Dr Campa received both is M.S. degree in Control Engineering (1996) and his and Ph.D. degree in Robotics and Automation (2000), from the University of Pisa, Italy. He has also worked at the Industrial Control Centre, Strathclyde University, UK, (1995) and at the Department of Aerospace Engineering, Georgia Institute of Technology, Atlanta, USA (1999). From 2000 to 2008 he served as faculty in the Flight Control Group at the Department of Aerospace Engineering, West Virginia University. His research at WVU involved system identification, sensor fusion, fault tolerant systems, machine vision, and adaptive and nonlinear control, especially applied to UAVs. He joined the Mathworks in 2009, where he currently works as a Technical Evangelist for the west coast area.

\section{Srikanth Gururajan, West Virginia University}

Dr. Gururajan is a Post-Doctoral Fellow in the Department of Mechanical \& Aerospace Engineering at West Virginia University. He received his Bachelor's degree from the University of Madras in 1997 and PhD from West Virginia University in 2006. His interests are in Flight Testing of UAVs, Aircraft Parameter Identification and Flight Controls, Neural Networks, Parallel and Distributed computing and Real-Time Operating Systems.

\section{Marcello Napolitano, West Virginia University}

Marcello R. Napolitano, was born in Pomigliano D'Arco, Italy. He received his M.S. Degree in Aeronautical Engineering from the University of Naples, Italy, 1985 and his Ph.D. Degree in Aeronautical Engineering from Oklahoma University (1989). In 1990 he joined the Department of Aerospace Engineering, West Virginia University, where is currently a Full Professor. His current research interests include Flight Control Systems, Unmanned Aerial Vehicles, Fault Tolerance, and Neural Networks. 


\title{
Enhancing Aerospace Engineering Education through Flight Testing Research
}

\begin{abstract}
This paper describes the typical workflow of projects conducted within the flight control group at West Virginia University (WVU) over the last decade. Researchers belonging to this group have acquired substantial and documented experience in the design, manufacturing and flight testing of small unmanned aircraft and successfully demonstrated autonomous GPS-based, closed-loop formation flight using 3 custom-built jet-powered UAVs in 2004. A typical flight control project at West Virginia University embodies several aspects of engineering education, as well as theoretical and practical topics, which are not covered in a conventional classroom or research setting. Specifically, undergraduate and graduate students involved within different research projects learn basic hardware and maintenance of small unmanned aerial vehicles, systems engineering, aircraft design, flight simulation and testing, as well as system identification and control design. Although aerospace engineering students are introduced to the fundamentals of flight dynamics in their coursework, the experience of project-based research enhances their understanding of the discipline as well as improves other critical engineering skills for future application in the professional world. This paper describes the work of several undergraduate and graduate students in the above-mentioned areas, with particular emphasis on the flight-testing and system identification phases.
\end{abstract}

\section{Introduction}

Aerospace engineering education at a college or university typically encompasses the study of aircraft, rockets, missiles, and spacecraft. An aerospace engineering curriculum consists of the fundamental concepts of flight, mathematics, and science, as well as the most recent advances in aerospace technology ${ }^{22}$. Laboratories or special class projects are often incorporated to enhance these lessons; however, this only constitutes a small portion of the class and curriculum. In fact after graduation, students still typically require substantial training in systems engineering before they can be fully effective within aerospace companies. Furthermore, while practicing engineers typically have one or two areas of expertise, engineers who understand their specialty in the context of the entire system are considered to be the most effective ${ }^{11}$ and tend to advance toward leading positions in their company or institution.

The Panel on Undergraduate Education lists the following goals of an undergraduate education in engineering ${ }^{14}$ :

- To prepare graduates to contribute to engineering practice by learning from professional engineering assignments;

- To prepare them for graduate study in engineering;

- To provide a base for lifelong learning and professional development.

Additionally, the Panel on Undergraduate Education emphasizes the need for students to have extensive laboratory experience in their curriculum. They argue that "the concept of the undergraduate student as an experimenter is fundamental to engineering education and to the role 
of a practicing engineer"14. The Panel also expresses that the laboratory is a "place to learn new and developing subject matter as well as insight into understanding of the validation and limitations of assumptions, prediction of the performance of complex systems, testing and compliance with specifications, and an exploration for new fundamental information"14. The Accreditation Board for Engineering and Technology (ABET) published the ABET Engineering Criteria in 1996 as "a mandate to educators to design curricula that could produce engineers with adequate skills to enter the job market" 9 . This report includes a set of 11 outcomes that graduates of baccalaureate engineering programs should obtain. These were divided into what was considered "hard" and "soft" skills, where hard skills refers to math and science aspects of the education and soft skills refers to professional abilities. The soft skills include "functioning on multidisciplinary teams; understanding professional and ethical responsibility; ability to communicate effectively; the broad education necessary to understand the impact of engineering solutions within a global, economic, environmental, and social context; recognition of the need for and an ability to engage in lifelong learning; and a knowledge of contemporary issues",

Flight testing research involves most aspects of aerospace engineering education: aircraft design, composite structures, flight dynamics, flight simulation, propulsion, and system engineering to name a few. Furthermore, flight testing courses and research allow students to use the knowledge gained in the classroom and apply it to a practical project from the ground up, which in turn greatly enhances both theoretical and practical understanding of the covered subjects and considerably improves learning and retention. Therefore, many universities have incorporated this type of hands-on work through either a dedicated course or a student organization where students can design, build, and fly small remote-controlled aircraft. The aim of these courses is to not only enhance the understanding of critical aerospace objectives, but also to improve design skills and encourage communication and teamwork ${ }^{18}$. The American Institute of Aeronautics and Astronautics Design, Build, Fly Competition provides a platform for teams of college students to design and construct a remote-controlled aircraft to compete in an annual challenge ${ }^{1}$. Each year the challenge structure is changed so teams will have to design a mission-specific aircraft for the competition. Teams from institutions such as Georgia Institute of Technology ${ }^{10}$, Oklahoma State University $^{13}$, University of Illinois at Urbana-Champaign ${ }^{19}$, University of Southern California ${ }^{20}$, Virginia Polytechnic Institute ${ }^{21}$, and West Virginia University ${ }^{22}$ annually participate in the Design/Build/Fly Competition through either a course offered at the school or a student organization. Many of these institutions also have excellent unmanned aerial vehicle (UAV) research groups, which allow both undergraduate and graduate students to further participate in hands-on engineering.

More than 30 undergraduate and graduate students at West Virginia University have worked on several projects at the Flight Controls Research Laboratory over the course of 12 years, and have had the opportunity become involved in an active flight testing program. Through these programs, students have presented their work at major conferences, earned scholarships and fellowships to help fund their education, and applied skills gained in their coursework. Many of these students now hold key job positions within important aerospace companies and institutions such as Northrop Grumman, Birhle Applied Research, the US Air Force, and NASA.

The following section of this paper briefly reviews the main ways in which students learn. Following sections will present aircraft design and building, flight testing research, parameter 
identification research, and control design. An overview of the student experience is given next, along with concluding remarks.

\section{Student Learning Methods}

It is believed that there are four basic learning modalities in humans: visual, auditory, kinesthetic, and tactile ${ }^{6,16}$. A visual learner, that is people for whom visual learning tends to be somewhat more effective with respect to the other modalities, tend to exhibit an improvement in information retention when it is presented through graphs, charts, or in reading material. Auditory learners have an improvement in comprehension and retention of information when it is presented through verbal communication such as lectures. Kinesthetic learners retain information through experimental learning and having the opportunity to be physically involved. Finally, "hands-on" experiments are particularly effective in improving information retention for "Tactile learners".

According to several studies, college students prefer a learning method parallel to their learning strengths and they excel on exams and fact comprehension when taught with their preferred learning modality ${ }^{5,8,16}$. These students also have an improved attitude and work efficiency when taught in their preferred learning modality as compared to students taught with an instructional style that is not their preferred method ${ }^{5,16}$.

Within a conventional collegiate aerospace engineering curriculum, visual learners are typically accommodated through reading material presented in course textbooks, and auditory learners grasp information best when it is presented through class lectures. These learning styles are the primary focus of most collegiate aerospace curriculums, with textbook reading and weekly lectures as the norm. Several institutions incorporate laboratory exercises or experimental courses to facilitate hands-on learning, which accommodates the kinesthetic and tactile learners. However, due to the limited availability of such courses, kinesthetic and tactile learners often find themselves at a disadvantage in a classroom setting. Therefore, by introducing more courses that incorporate hands-on and experimental learning, kinesthetic and tactile learners will be accommodated through the curriculum. Even more importantly, hands on and experimental learning has been shown to considerably improve learning, understanding, and information retention for all kind of learners, since it allows the students to effectively review and apply the knowledge acquired in the classroom, while at the same time complementing it with practical knowledge that can only be acquired by actually carrying out tasks within a real-world context.

\section{Flight Testing Research at West Virginia University}

Researchers at the Flight Controls Research Lab at West Virginia University have been conducting flight test research with several unmanned aerial vehicle platforms for over 12 years. With these projects, both undergraduate and graduate students have been afforded the opportunity to work in systems engineering, aircraft design, avionics design, and aircraft maintenance. Major projects have included the design of several nonlinear and adaptive control laws, investigations in fault-tolerant systems and autonomous formation flight. Through these projects, students have utilized their knowledge and skills gained through their coursework. 
As an example of the various aircraft built at West Virginia University over the last decade, the YF-22 will be considered in this section. Three WVU YF-22 sub-scale unmanned test bed aircraft were designed, built, and instrumented by five faculty members, four graduate research assistants, and one undergraduate student at West Virginia University, over the course of 2 years, for the formation flight project ${ }^{12}$. The first step of the project was to design the aircraft, including aerodynamics, propulsion layout, and payload bays, which was completed using CAD software. Some of the design specifications for the aircraft included the following: the capability of lifting a 10 pound payload, the fuel capacity to sustain a 12 to 15 minute flight test, and the ability to maintain a stable testbed in flight. The produced drawings were utilized in the design of the aircraft molds and overall construction of the aircraft. Figure 1 shows the CAD design of the YF22 aircraft that was translated into the construction, shown in Figure 2.

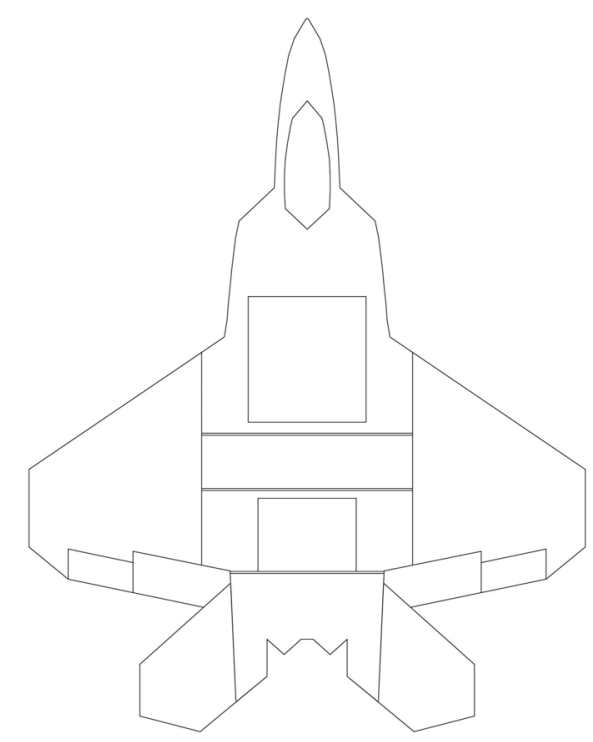

Figure 1: CAD Design of the WVU YF-22 Aircraft ${ }^{12}$ 


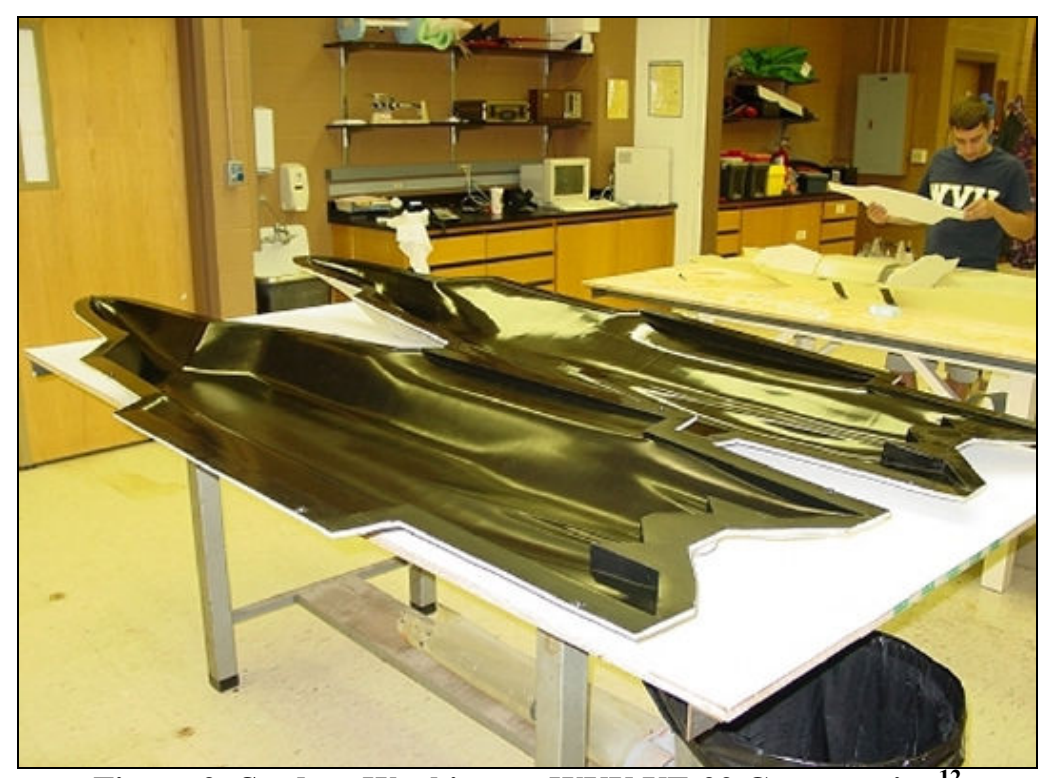

Figure 2: Student Working on WVU YF-22 Construction ${ }^{12}$

The molds shown in Figure 2 were used to lay-up carbon fiber and fiberglass shells to constitute the aircraft body. The students worked to ensure that the aircraft body was strong enough to support the weight of the planned avionics payload and fuel, and that the aircraft was built as specified in the design. Figure 3 shows the finished aircraft after the final paint scheme was applied by the students.

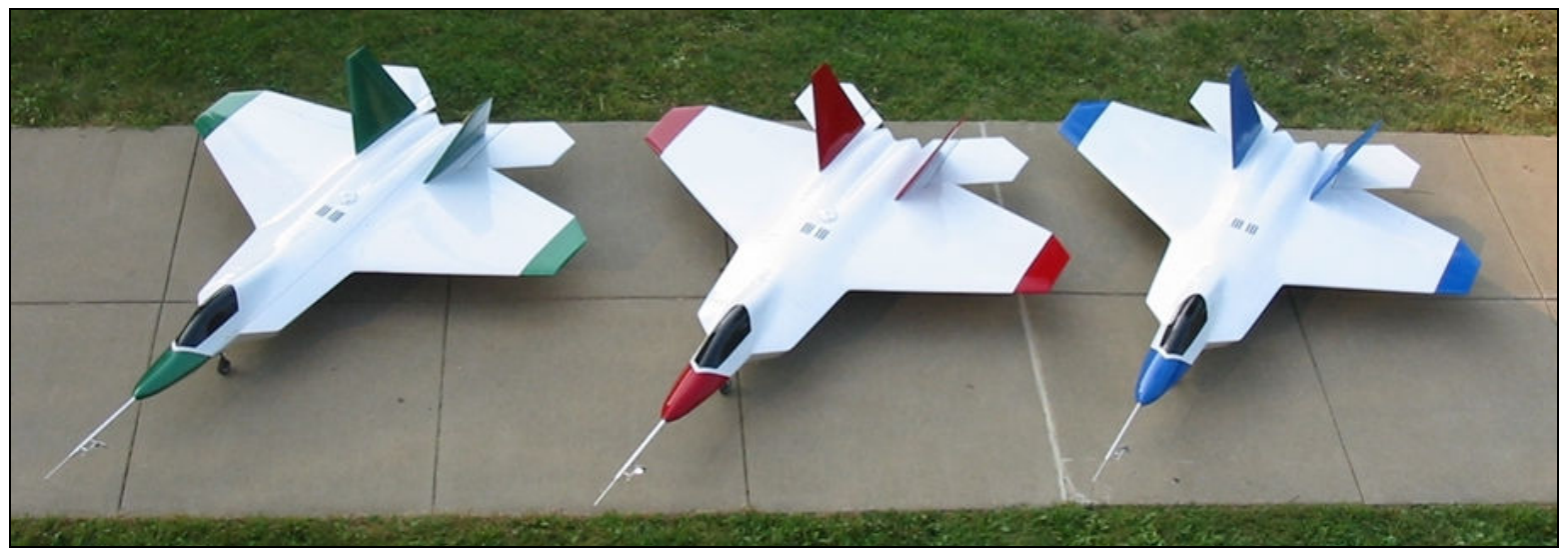

Figure 3: WVU YF-22 Aircraft Fleet

The WVU YF-22 aircraft was designed for testing and evaluation of flight control laws; therefore, the aircraft was fitted with an on-board computer and a complete suite of sensors for measuring a variety of flight parameters. The electronic payload consists of a PC-104 form factor, a GPS receiver, customized electronic boards, inertial measurement unit, vertical gyro, air data probe, absolute and differential pressure sensors, and potentiometers for measuring the control surface deflections. The on-board computer features software that serves to execute the flight control scheme. The operating system was based on a Linux kernel (Version 2.6.9), patched with the Real Time Application Interface (RTAI, Version 3.2), allowing the execution of the flight control software with strict timing constraints. Due to the constraints of the on-board storage, the RTAI patched kernel was compiled with a minimum amount of features and 
Busybox software, which provides the required Linux utilities. The top portion of Figure 4 shows the location of the instrumentation package within the cargo bay while the bottom section of the figure shows the internal PC-104 assembly of the on-board computer (OBC) ${ }^{3}$.

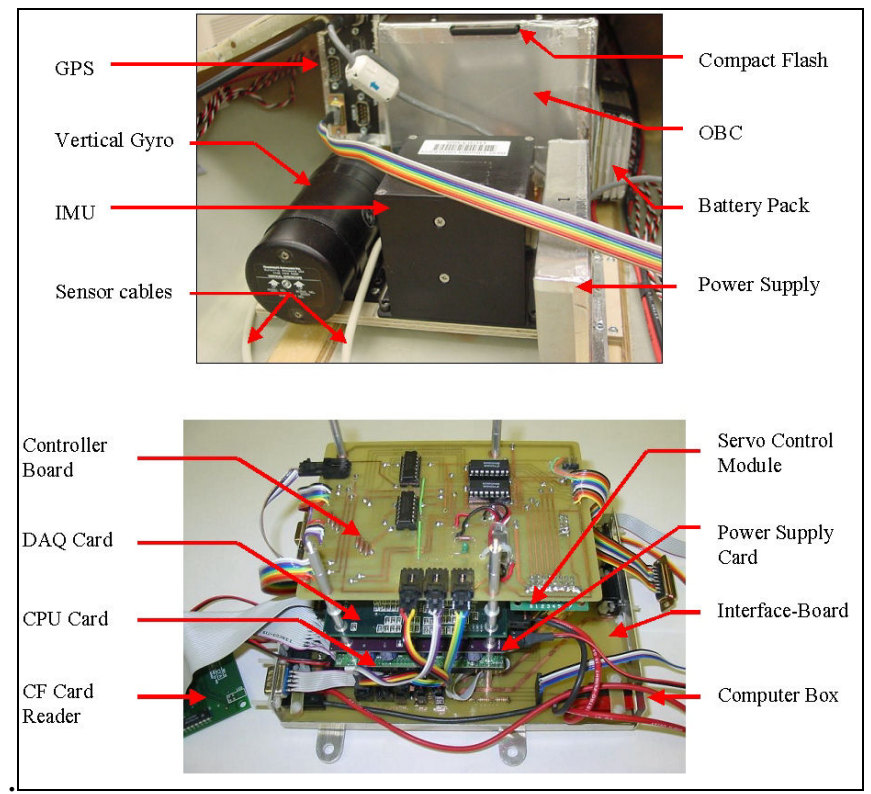

Figure 4: On-Board Instrumentation Package ${ }^{3}$

Special attention was given to the design, manufacturing, and installation of both the customized and "off-the-shelf" components with the goal of avoiding or mitigating electromagnetic interference (EMI) problems. In particular, aluminum enclosures were designed and manufactured for shielding most of the hardware components, and ferrite RF chokes were inserted along both power and signal cables ${ }^{3}$.

Following the construction and instrumentation of the aircraft, students were involved in the flight testing process and procedures.

\section{Flight Testing}

Flight testing activities - which are conducted at the Louis-Bennett Airfield at WVU Jackson's Mill, WV, featuring a 3,300 ft. paved runway - require the collaboration of the entire group of faculty and students. Prior to traveling to the airfield, several students assess the aircraft hardware and run ground tests of flight control software. The aircraft maintenance is conducted by all of the students in the group, both undergraduate and graduate. This enables them to get a sense of how the aircraft works when it is functioning properly and to identify when a component is having issues.

On the day of a flight, students also share the responsibility of packing several items for the flight tests, including the aircraft, fuel, tools, batteries, weather station, and other supporting equipment. Once at the field, each student has a set of responsibilities to prepare the aircraft for flight: ground testing the software, charging the batteries, reviewing aircraft hardware, checking 
the runway for debris, and fueling the aircraft are just some of the responsibilities given to students in the program.

Prior to flying, a graduate student verifies the flight path in a Matlab/Simulink environment developed specifically for the YF-22. The student adjusts wind conditions and maneuver combinations within the simulation to observe the angular rates and behavior of the aircraft before flight-testing. This ensures that the aircraft will remain within safe bounds of the airfield and the structural integrity of the aircraft will not be compromised.

Whenever data acquisition for Parameter Identification (PID) purposes has to be performed, a lead graduate student for PID will set up the aircraft software and perform a ground test at the field. On several occasions, an undergraduate student has shadowed the graduate lead to become familiar with the ground test process.

Another graduate student will take lead for checking the avionics and hardware, and he or she will review the instrumentation status to verify that everything will perform as expected. An undergraduate student will assist with this task and check the landing gears, fuel the aircraft, and help with other maintenance issues. The aircraft is also checked over by the pilot who will be remotely controlling the vehicle for take off and landings. Once all of the checks are completed, the software is loaded, and the aircraft is fueled.

Whenever PID is the purpose of the flight, the lead graduate student will call a pilot briefing and explain what maneuvers or procedures are required for the upcoming flight test. Typically, PID maneuvers are injected as doublets on the control surfaces These doublet maneuvers excite the aircraft longitudinal and lateral-directional dynamics, which in turn are used to derive the aircraft mathematical model. We have found the pilot briefing experience to be invaluable in reinforcing students' communication skills. Once this briefing is over, the aircraft is ready for takeoff and is carried out to the runway. A graduate student will remain with the pilot throughout the flight and act as a co-pilot to help guide the flight test, as shown in Figure 5 during a takeoff sequence. Once the flight is over, one of the team members conducts a post-flight debriefing with the group. Whenever the purpose of the flight is other than PID, the control design student will take the lead to set up the aircraft, brief the pilot, and conduct the post-flight debriefing. 


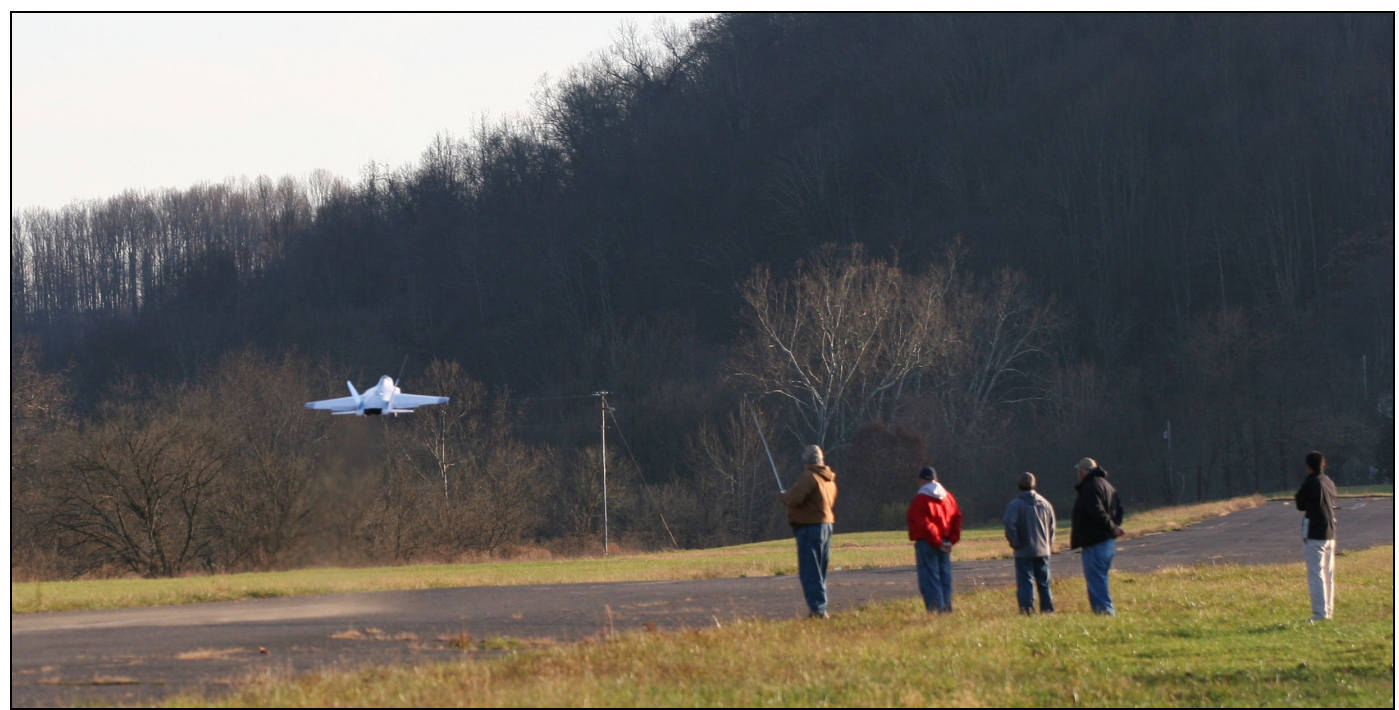

Figure 5: WVU YF-22 Aircraft Takeoff from Louis-Bennett Airfield

\section{Parameter Identification}

Once the flight tests are completed, the data is reviewed by the graduate PID lead, who uses the flight data to derive the mathematical model of the aircraft. In order to successfully identify a mathematical model for the YF-22 aircraft, the accurate moments of inertia had to be calculated. This was a separate effort assigned to a graduate student and two undergraduates to determine these values. This is a topic covered in coursework; however, methods to experimentally determine these values are not expanded upon. Figure 6 shows the graduate student working with the aircraft apparatus used to find the moments of inertia.

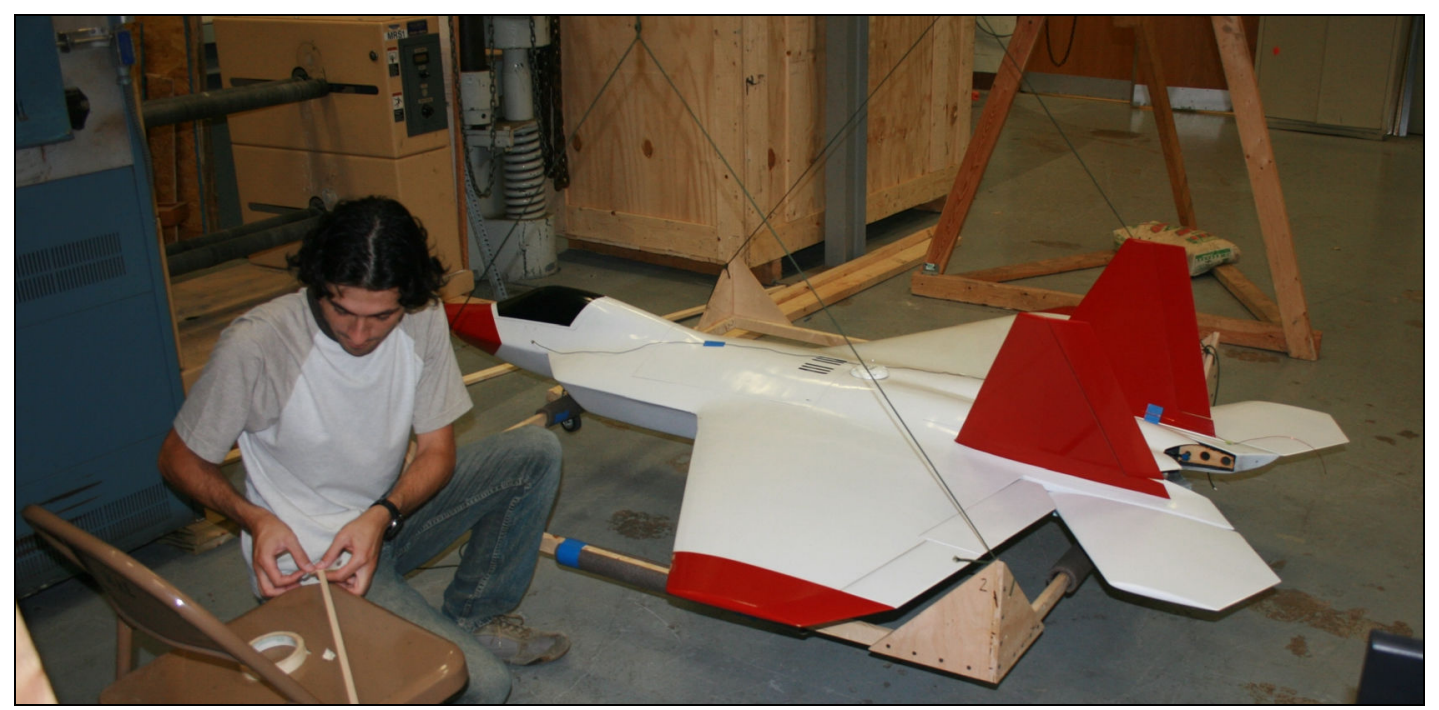

Figure 6: Graduate Student Working with WVU YF-22 Aircraft to Determine Moments of Inertia

Once the moments of inertia were calculated, the PID lead was able to derive the aircraft mathematical model from flight data. First, the flight data with the PID doublet maneuvers was segmented and run through the Matlab System Identification Toolbox to obtain the linear 
mathematical model for the aircraft. Figure 7 shows a sample of segmented flight data with a doublet maneuver that the student used for the identification process.

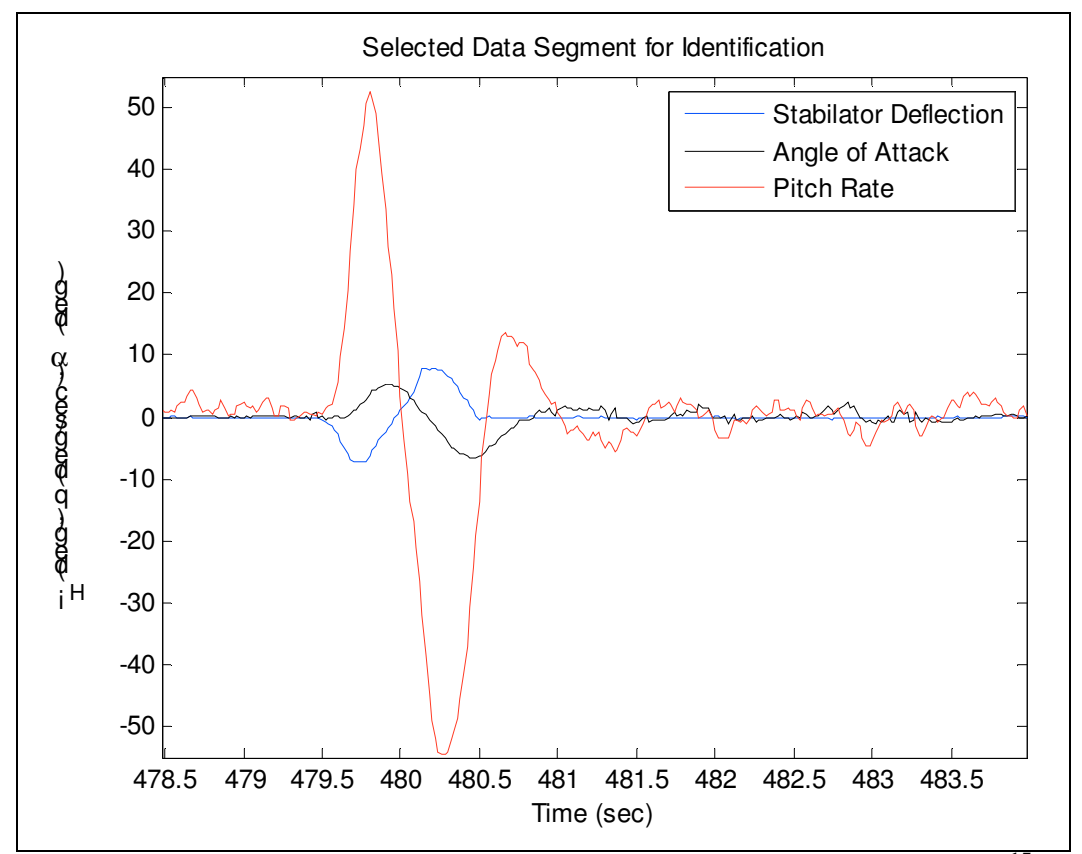

Figure 7: Flight Data Segment used for Parameter Identification ${ }^{15}$

A graduate student primarily conducted this portion of the study; however, an undergraduate student reviewed the flight data segments to verify their quality for use in the simulations. From these data sets, the linear model of the aircraft dynamics was derived. This included matrices representing both the longitudinal and lateral-directional dynamics. The next step was to determine the aircraft aerodynamic derivatives by converting the linear model to provide the initial nonlinear coefficients for optimization. The relationships for determining the coefficients of the matrices in the linear models starting from the values of the aerodynamic derivatives and geometric-inertial parameters are well known ${ }^{7}$. By inverting these relationships, and by using the values of the geometric and inertial parameters obtained experimentally, it is possible to evaluate the initial values for each of the aerodynamic derivatives.

The Matlab ${ }^{\circledR}$ function 'costfcn' was developed with the purpose of simulating the nonlinear dynamics, using the control deflections from the entire identification data set as inputs for the nonlinear aircraft model, and calculating the value of a cost function based on the root-meansquare of the difference between the 'actual' outputs (i.e. the measured output values from the identification data set) and the 'simulated' outputs (i.e. the outputs from the nonlinear aircraft model). Therefore, the main input argument of 'costfcn' is a vector containing a set of values for the aerodynamic derivatives. The 'fmincon' function - featuring a constrained optimization of a multivariable function using a Sequential Quadratic Programming technique ${ }^{17}$ - was then used to iteratively minimize the cost function implemented within 'costfcn'. Essentially 'fmincon' iteratively calls upon 'costfcn' with different inputs, until the set of aerodynamic derivatives provides the best fit with the flight data. An optimized nonlinear model data set is shown in Figures 8 and 9 for the pitch rate and yaw rate, respectively. These plots show that the nonlinear model of the aircraft accurately replicates the actual aircraft flight behavior. 


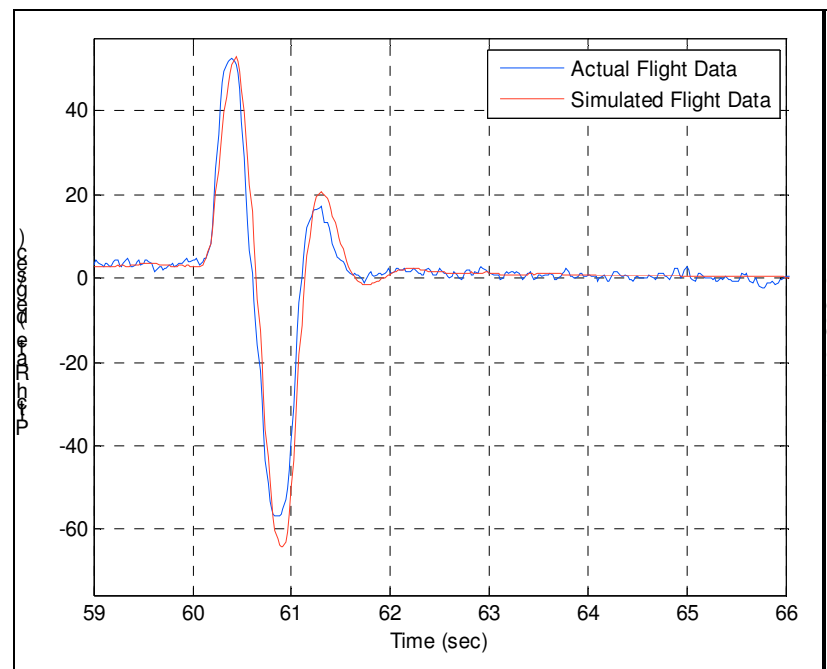

Figure 8: Pitch Rate Response

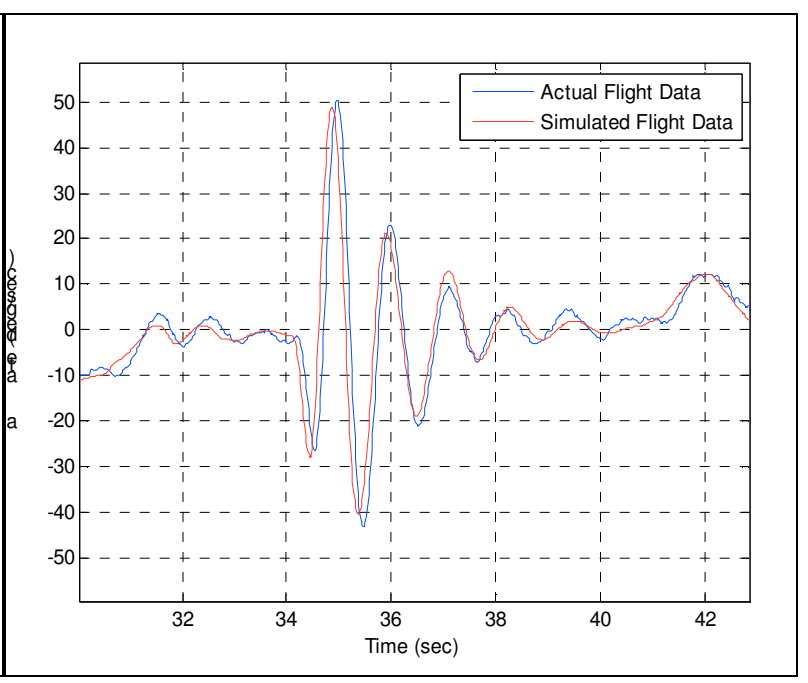

Figure 9: Yaw Rate Response

Once the optimized nonlinear model was derived, a simulation study was conducted to validate the model. The nonlinear model was implemented into a Simulink environment developed to simulate the aircraft following a predefined path used in flight tests. Within this simulator, the trim conditions of the WVU YF-22 were implemented to provide a more accurate simulation to mimic the aircraft flight performance. Figures 10 and 11 show the resulting two- and threedimensional simulated flight paths (shown in red) versus the predefined path (shown in blue).

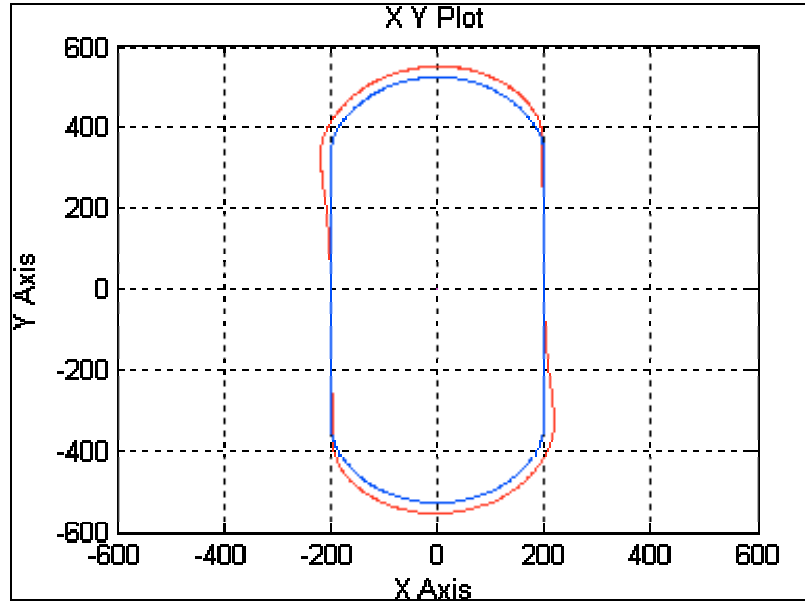

Figure 10: Two-Dimensional Simulated Flight Path

(VL: Blue, Simulated Follower: Red)

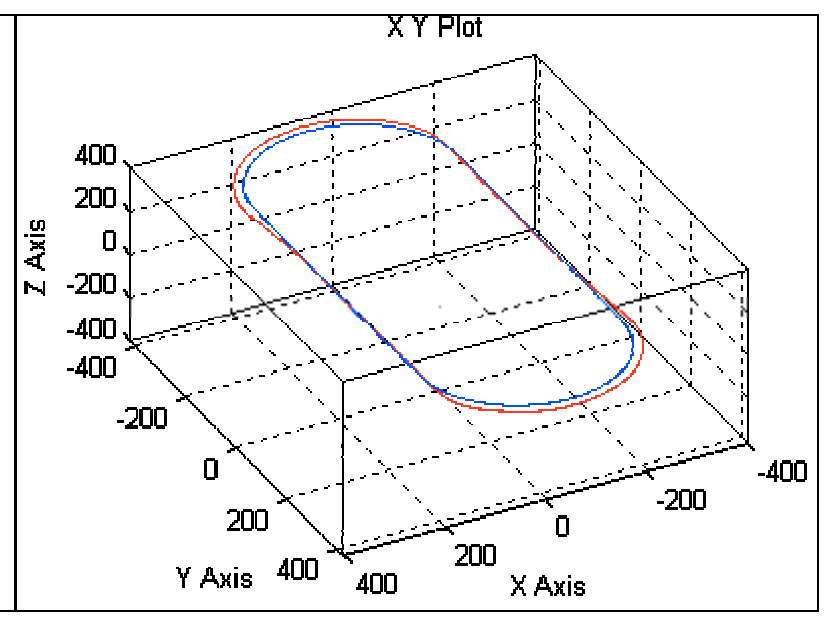

Figure 11: Three-Dimensional Simulated Flight Path (VL: Blue, Simulated Follower: Red)

Next, the same process was performed with the aircraft flight data sets incorporating locked control surfaces, a typical actuator failure scenario. During PID flight testing, the aircraft computer was programmed to lock a specified control surface at the trim position while the corresponding surface of the pair completed a double maneuver. This allowed flight data to be collected reflecting the contribution of an individual control surface on the aircraft dynamics. Specifically, moving an individual control surface causes a cross-coupling between the longitudinal and lateral-directional dynamics. For example, the deflection of an individual elevator will cause a rolling and yawing response in addition to the typical pitching movement. 
This cross-coupling requires accurate modeling for application within fault-tolerant flight control systems, which is the ultimate goal of this particular PID effort. This model was named the Coupled Dynamics with Independent Control Effectors (CoDICE) model for the dynamic behaviors of the aircraft it represents.

The linear CoDICE model was derived by combining the nominal longitudinal and lateraldirectional linear model state matrices derived from flight data with no failures. The resulting state matrix was essentially a combination of the nominal longitudinal and lateral-directional state matrices, including the velocity, angle of attack, angle of sideslip, roll rate, pitch rate, yaw rate, pitch angle, and bank angle components, and it is considered to remain unchanged for this class of failures. The input matrix, however, accounts for the decoupled control surfaces by incorporating the six inputs individually. The nominal linear model was essentially derived by dividing the combined stabilator, aileron, and rudder input matrix components into the six individual components, thus halving the numeric values for each of the pair when reassigned to the surfaces.

The modeling procedure described above does not account for some components of the input matrix at 'failure' conditions. These components include the individual stabilator effects on the lateral-directional states and the individual aileron and rudder effects on the longitudinal states. In this case, the individual stabilator inputs had an effect on the angle of sideslip, roll rate, and yaw rate, and the individual aileron inputs had an effect on the angle of attack and pitch rate which is not observed under nominal conditions. For this study, as rudder failures were not incorporated, their contributions to the longitudinal dynamics were not accounted for. A Simulink ${ }^{\circledR}$ scheme was developed using the Parameter Identification Library developed at $\mathrm{WVU}^{4}$ to evaluate a section of flight data where the control surface failure occurred and identify the unknown input matrix components using Fourier Transform Regression (FTR) method. The outputs of the FTR Simulink scheme represent the individual control surface coefficients in the input matrix for the cross-coupling behavior.

The next task was to determine the aerodynamic coefficients by converting the CoDICE linear model to provide the initial nonlinear model values for optimization. The relationships for evaluating the coefficients of the matrices in the CoDICE linear model starting from the values of the aerodynamic derivatives and geometric-inertial parameters had to be established. By inverting these relationships similarly to the method in the nominal nonlinear model and using the experimental values of the geometric and inertial parameters, it was possible to evaluate the initial values for each of the aerodynamic derivatives. Since the 'failures' observed in this study did not include damaged control surfaces, the nominal nonlinear model stability and control derivatives remain consistent in this model. This approach utilized the final nominal nonlinear model previously identified with the contributions from the decoupled control surfaces. This enabled the effects of each individual control surface on the aerodynamic coefficients to be separately determined, and the coefficients were split by incorporating the surface sign conventions. New 'unknown' coefficients had to be identified as well, since they were not identifiable under the nominal flight conditions. These 'unknown' coefficients represent the cross-coupling behavior of the aircraft dynamics under these locked actuator conditions. 
In order to identify the 'unknown' coefficients, the CoDICE linear aircraft model was converted to a CoDICE nonlinear model. The 'unknown' coefficients derived from this linear to nonlinear conversion were implemented into the nominal nonlinear model (previously derived) with the decoupled control surfaces. This model served as the starting point for the iterative optimization process. As in the nominal nonlinear model optimization process, the Matlab ${ }^{\circledR}$ function ' $\operatorname{costf} c n$ ' and 'fmincon' were utilized with the purpose of simulating and optimizing the nonlinear aircraft dynamics. Again, damage to the aircraft and control surfaces was not considered, so it is valid to assume that the coefficients derived in the nominal nonlinear model still apply under locked actuator conditions; therefore, only the new 'unknown' coefficients were run through the iterative optimization process. The optimization was conducted around two sets of flight data that incorporated a locked control surface: one set of flight data exhibited the left aileron locked at trim and a second set exhibited the left stabilator locked at trim during an attempted doublet maneuver. From these maneuvers, the individual contributions of these control surfaces could be observed through the cross-coupling of the aircraft dynamics.

This CoDICE nonlinear model is still in the process of being optimized. This nonlinear model will be validated through a series of simulation studies and will be tested in flight during the summer of 2010. After successful flight tests, the model will be implemented by another graduate student into a fault-tolerant flight control system.

\section{Control Design and Validation}

The evaluation and validation of an aircraft model and control laws is a vital check prior to actual flight testing activities for a new system. A simulation environment - shown in Figure 12 was developed using Simulink that incorporates the nonlinear aircraft model and can be used for flight control evaluations prior to the actual flight tests.

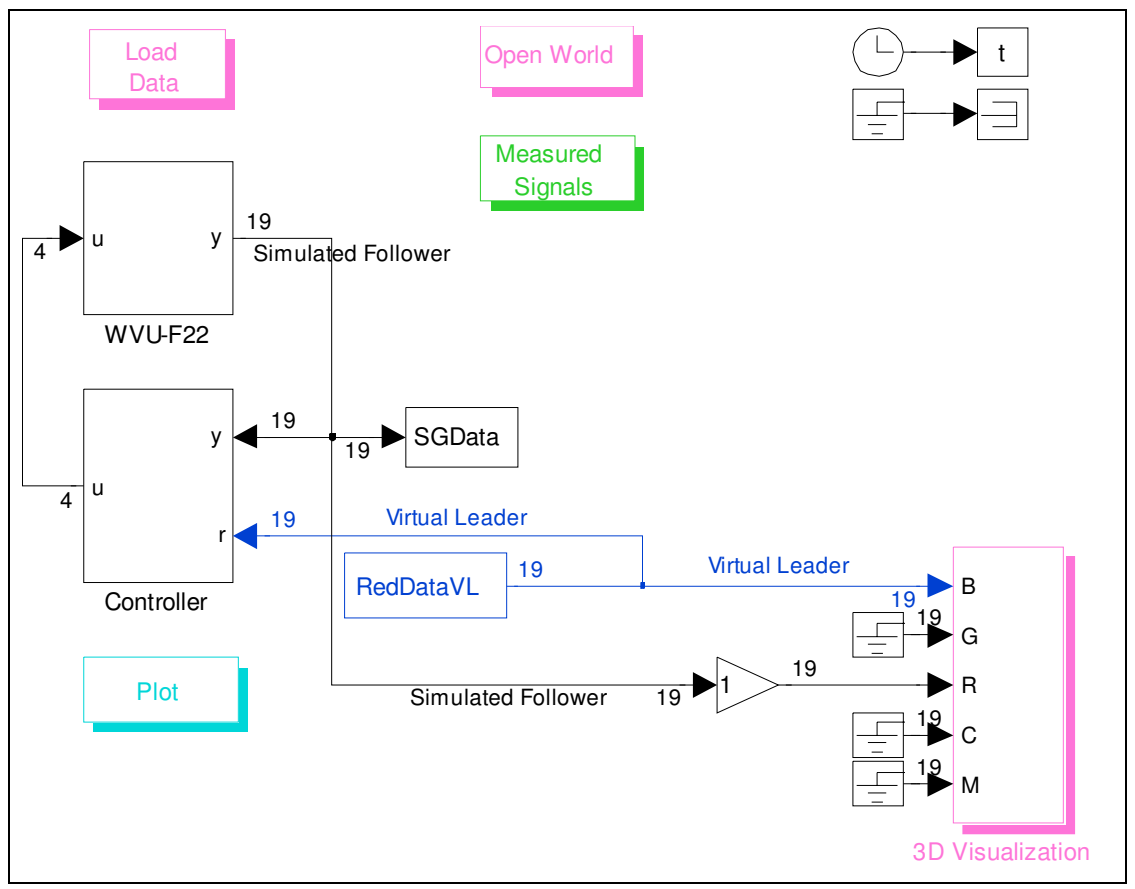

Figure 12: WVU YF-22 Simulink Simulation Environment 
This simulation environment allows for the modeling of wind effects on the aircraft flight path as well as multiple aircraft simulations (used previously for the formation flight project). Within this environment for the PID study, a predefined GPS coordinate path may be implemented as the desired flight path, or what is called a Virtual Leader. From this a follower aircraft, which is represented by the derived nonlinear aircraft model, tries to stay with the Virtual Leader on its flight path. This simulation environment also allows for the control system to autonomously inject maneuvers on the control surfaces during the simulation, similar to those performed in actual flight. This simulation also has a three-dimensional visualization environment, (using the Simulink 3D Animation ${ }^{\circledR}$ tool), which visually represents the YF-22 aircraft behavior. Figure 13 shows a sample from a flight simulation of this environment.

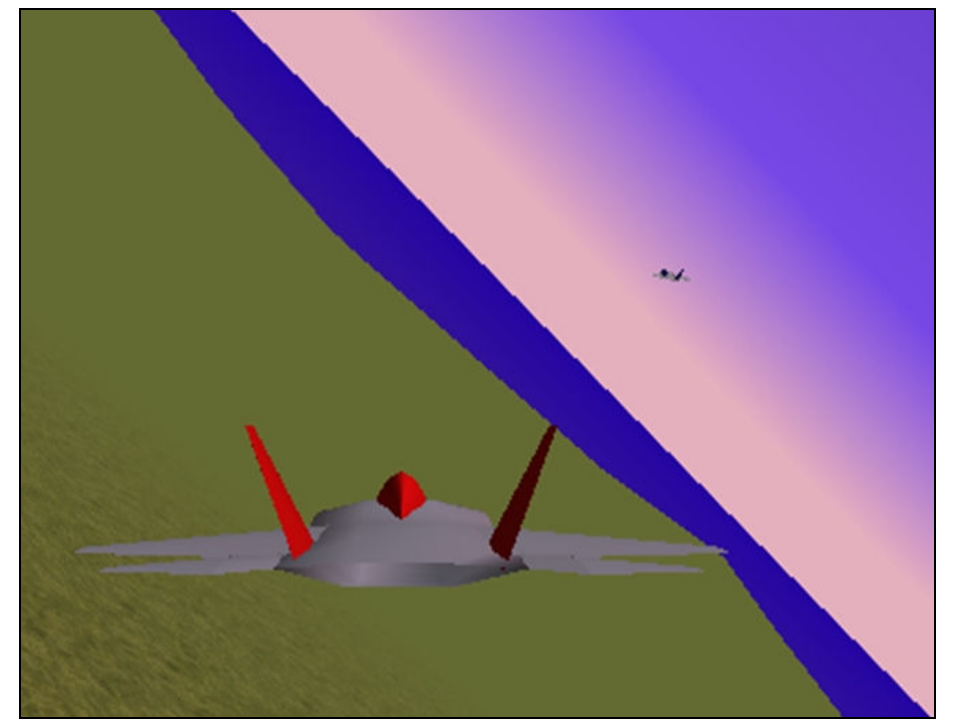

Figure 13: Three-Dimensional Virtual WVU YF-22 Visualization Environment

The CoDICE model derived from the PID study will be implemented into a fault-tolerant flight control system by another graduate student team. This fault-tolerant flight control system aims to improve the robustness of the aircraft to both sensor and actuator failures. The CoDICE model will be directly applied in the case of an actuator failure where coupling of the aircraft dynamics will be prevalent. This class of fault-tolerant flight control laws seeks to detect when a failure occurs, identify the failure, and accommodate for the failure using other available control surfaces or sensors. In general, the development of an integrated adaptive flight control system capable of detecting, identifying, and accommodating for both sensor and actuator failures in real-time could considerably improve the safety of flights in both the civilian and military sectors.

\section{Student Experience}

Undergraduate and graduate students gain more than enhancing their classroom education alone, these students have the opportunities to earn scholarships and give formal presentations for their efforts with flight testing research. 
Several of the undergraduate students that worked with the Flight Control Research Lab earned scholarships through the West Virginia NASA Space Grant Consortium to assist in financing their education. These undergraduate students also had an opportunity to formally present their work at a public forum, at the Undergraduate Research Day at the Capitol event in Charleston, West Virginia, which afforded them the experience of presenting technically advanced material to West Virginia state legislators as they will often be required to do in their careers. The graduate students also presented their published work at several national and state conferences including the American Institute of Aeronautics and Astronautics (AIAA) Guidance, Navigation, and Control Conference, the AIAA Young Professional and Student Educational Conference, and the West Virginia STAR Symposium. The presentation skills gained through these opportunities undoubtedly improves the communication ability of these students for their future careers.

\section{Student Opinion Survey}

Two surveys were developed to gather data on the benefits of flight testing research and/or coursework to aerospace educational development based on the perception of the students. The surveys were divided into undergraduate and graduate categories to obtain different metrics that were more relevant to the respective student groups. A similar method was conducted by Brodeur et al. where a survey distributed at the end of the semester reflected the opinions of the students on how they viewed the course and its benefits to their overall education ${ }^{2}$. Where some of the questions were the same between the undergraduate and graduate students, they are reported together.

For the graduate survey, $80.0 \%$ of the participants agreed that their graduate research experience with a UAV flight testing program built upon concepts learned through their graduate and undergraduate coursework. $100.0 \%$ of the participants agreed that UAV flight testing research introduced them to new concepts not covered in the classroom, including "exposure to hardware electronics, sensors, and software development." $100.0 \%$ of the participants agreed that UAV flight testing research improved their understanding of flight mechanics and aircraft design and improved their problem solving skills. One student commented, "Improving my problem solving skills is what I attribute as the biggest influence flight testing has made with respect to my graduate research experience."

Sophomores, juniors, and seniors participated in the undergraduate survey. Many of these students participated in the Design, Build, Fly course at West Virginia University, and their responses reflect their experiences. Of the undergraduate students completing the survey, only $18.2 \%$ of them had worked with a UAV flight testing program for undergraduate research; however, the other $81.8 \%$ had participated in the Design, Build, Fly course. $100.0 \%$ of the students participating in the survey agreed that UAV flight testing research or coursework built upon concepts they cover in their aerospace curriculum. Of the undergraduate students, $63.7 \%$ of them have participated in an internship or co-op, and all of them believe that their flight testing research or coursework experiences better prepared them for their position. $90.9 \%$ of the undergraduate students completing this survey agreed that their flight testing research or course 
introduced them to new concepts not covered in their other coursework. Responses varied in this category, with students commenting as follows:

- I learned fabrication of aircraft components using composites.

- I learned building techniques, teamwork, and composites.

- I learned how to complete CAD drawings, detailed aircraft design, and life-size modeling.

- My experiences that were not covered in my other coursework include difficult tasks such as full system integration and building real hardware. I was also introduced to system engineering, team management, scheduling, and goal/requirement setting.

As with the graduate students, $100.0 \%$ of the undergraduate students participating in the survey agreed that their UAV flight testing research or course experience improved their understanding of aircraft design and flight mechanics as well as their problem solving skills. Students had additional comments regarding their improved understanding of concepts covered in their typical aerospace engineering coursework, which highlights the potential benefits of hands-on work with aircraft for all learning types. One student, who admitted some difficulty in understanding some material covered in lectures and reading, expressed the following:

- I often found myself confused or struggling to understand concepts in my flight mechanics course, and after the instructor introduced small aircraft models as teaching tools, I began to grasp some of the concepts. My participation in flight testing coursework (Design, Build, Fly) also increased my understanding as I was able to physically work with the aircraft.

The students participating in the survey are representative of typical aerospace engineering students with varying learning styles. Most of the students found that hands-on work with an aircraft was beneficial to their education, whether it was building upon concepts they already understood or clarifying concepts not grasped from reading material and instructor lectures.

\section{Conclusions and Recommendations}

UAV flight testing research and coursework enhance the basic education obtained in a typical aerospace engineering curriculum. Colleges and universities that have incorporated a Design, Build, Fly course into their curriculum have substantially increased their students' chances for a successful aerospace career.

West Virginia University has incorporated both flight testing research through the Flight Control Research Lab and the UAV Design, Build, Fly course to enhance their aerospace curriculum. Student surveys conducted at West Virginia University show that students gained confidence in their abilities and believed that these programs enhanced their understanding of material they learned in their courses and improved their problem solving skills.

The authors wish to encourage schools that do not have an active flight testing research program to look into implementing one in their curriculum. Although many colleges and universities find themselves having a difficult time funding such a design-build-fly program, technology 
advancements in the last decade have allowed the possibility of purchasing several small and inexpensive RC aircraft kits that students could use to build and instrument an aircraft as a team.

\section{Bibliography}

1. American Institute of Aeronautics and Astronautics. "Design Build Fly Competition", Accessed December 10, 2009. http://www.aiaadbf.org/.

2. Brodeur, D.R., Young, P.W., Blair, K.B. Problem-Based Learning in Aerospace Engineering Education. Proceedings from 2002 American Society for Engineering Education Annual Conference and Exposition.

3. Campa, G., Gu, Y., Seanor, B., Napolitano, M.R., Pollini, L., and Fravolini, M.L., Design and Flight Testing of Non-Linear Formation Control Laws, Control Practice Engineering: A Journal of the International Federation of Automatic Control, 15 (2007), 1077-1092

4. Campa, G. "PIL, Parameter Identification Library", 2008. http://wwww.mathworks.com/matlabcentral/

5. Domino, G. Interactive Effects of Achievement Orientation and Teaching Style on Academic Achievement. ACT Research Report, 39, 1-9. 1979.

6. Dunn, R. Learning Styles and its Relation to Exceptionality at Both Ends of the Spectrum. Exceptional Children, 49, 496-506. 1983.

7. Etkin, B., Dynamics of Atmospheric Flight. John Wiley \& Sons, Inc. 1972.

8. Farr, B.J. Individual Differences in Learning: Predicting One's More Effective Learning Modality. Unpublished doctoral dissertation, Catholic University, 1971.

9. Galloway, P.D., The $21^{\text {st }}$-Century Engineer: A Proposal for Engineering Education Reform. American Society of Civil Engineers Press. Reston, VA. 2008.

10. Georgia Institute of Technology, "Design Build Fly", Accessed March 3, 2010. http://www.dbf.gatech.edu/.

11. Joshi, D.S. Viewpoint: Aerospace Education for 2000 and Beyond. International Journal of Engineering Education, Vol. 13, No. 2, pg 138-142.

12. Napolitano, M.R., Development of Formation Flight Control Algorithms Using 3 YF-22 Flying Models. AFOSR Grant F49620-01-1-0373. April 2005.

13. Oklahoma State University, "Aerospace Design”, Accessed March 3, 2010. http://aerodesign.okstate.edu/.

14. Panel on Undergraduate Engineering Education, Engineering Undergraduate Education. National Academy Press. Washington, DC. 1986.

15. Phillips, K., Campa, G., Gururajan, S., Seanor, B., Napolitano, M.R., Gu, Y., and Fravolini, M.L., Parameter Identification for Application within a Fault-Tolerant Flight Control System. AIAA Flight Mechanics Conference Proceedings. Chicago, IL. August 2009.

16. Reid, J.M. The Learning Style Preferences of ESL Students. Teachers of English to Speakers of Other Languages, Inc. TESOL Quarterly, Vol. 21, No. 1, pg 87-111.

17. Simulink, Simulation, and Model Based Design, The Mathworks Inc., Natick, MA, 2007

18. Sullivan, J.P., \& Watkins, W.A. A Design/Build/Test Environment for Aerospace Education. $38^{\text {th }}$ Aerospace Sciences Meeting and Exhibit. 10-13 January 2000, Reno, NV. AIAA $2000-0525$.

19. University of Illinois, "Design Build Fly Projects", Accessed March 3, 2010. http://www.ae.illinois.edu/DBF/.

20. University of Southern California, "USC Aero Design Team", Accessed March 3, 2010. http://www-scf.usc.edu/ uscadt/.

21. Virginia Polytechnic Institute, "Virginia Tech Design Build Fly", Accessed March 3, 2010. http://www.vtdbf.org/.

22. West Virginia University Undergraduate Catalog 2009-2010. West Virginia University Purinton House. Series 01, No. 2, April 2009. ISSN 0362-3009. 